\title{
sciendo
}

\section{Training Loads, Wellness And Performance Before and During Tapering for a Water-Polo Tournament}

\author{
by \\ Petros G. Botonis ${ }^{1}$, Argyris G. Toubekis ${ }^{1}$, Theodoros I. Platanou ${ }^{1}$
}

We investigated the effectiveness of a short-duration training period including an overloaded (weeks 1 and 2) and a reduced training load period (weeks 3 and 4) on wellness, swimming performance and a perceived internal training load in eight high-level water-polo players preparing for play-offs. The internal training load was estimated daily using the rating of perceived exertion (RPE) and session duration (session-RPE). Perceived ratings of wellness (fatigue, muscle soreness, sleep quality, stress level and mood) were assessed daily. Swimming performance was evaluated through 400$m$ and 20- $m$ tests performed before (baseline) and after the end of weeks 2 and 4 . In weeks 3 and 4, the internal training load was reduced by $19.0 \pm 3.8$ and $36.0 \pm 4.7 \%$, respectively, compared to week $1(p=0.00)$. Wellness was improved in week $4(20.4 \pm 2.8 \mathrm{AU})$ compared to week 1 and week 2 by $16.0 \pm 2.2$ and $17.3 \pm 2.9 \mathrm{AU}$, respectively $(p=0.001)$. At the end of week 4, swimming performance at 400- $m$ and 20-m tests (299.0 \pm 10.2 and $10.2 \pm 0.3 \mathrm{~s}$ ) was improved compared to baseline values $(301.4 \pm 10.9$ and $10.4 \pm 0.4 s, p<0.05)$ and the overloading training period (week $2 ; 302.9 \pm 9.0$ and $10.4 \pm 0.4 s, p<0.05)$. High correlations were observed between the percentage reduction of the internal training load from week 4 to week $1(-25.3 \pm 5.5 \%)$ and the respective changes in $20-m$ time $(-2.1 \pm 2.2 \%, r=0.88, p<0.01)$, fatigue perception $(39.6 \pm 27.1 \%)$, muscle soreness $(32.5 \pm 26.6 \%)$, stress levels $(25.6 \pm 15.1 \%)$ and the overall wellness scores $(28.6 \pm 21.9 \%, r=0.74-0.79, p<0.05)$. The reduction of the internal training load improved the overall perceived wellness and swimming performance of players. The aforementioned periodization approach may be an effective training strategy in the lead-up to play-off tournaments.

Key words: team-sports, water polo training, fatigue, recovery.

\section{Introduction}

High-level water-polo players participate in a prolonged competitive period including preseason and in-season training. Especially during the in-season period, high-level players participate in an official match almost every week and train up to nine times per week (Lupo et al., 2014b). In most of the European Leagues, the competitive period is organized in two phases. In the first phase, all teams compete against each other twice, aiming at adding victories to classification. In the second phase, only the top classified teams compete in a play-off tournament requiring participation in a series of critical matches within a period of about fifteen days for the nomination of the champion team. As such, elite water-polo players need to maintain high levels of performance throughout the season achieving their peak performance in the play-offs.

Empirical evidence suggests that peak performance in the play-offs is expected after a taper training cycle aiming to maximize players' physical abilities while reducing the likelihood of fatigue (Mujika, 2009). This should be achieved by manipulating the training loads in the period between the first (competitive period) and the second phase (play-offs) of the season when it is possible to apply two short-duration phases including overloading and a subsequent training

1 - Department of Aquatic Sports, School of Physical Education and Sports Science, University of Athens, Athens, Greece. 
load reduction (i.e. taper) as it is applied in individual sports (Bosquet et al., 2007). In individual sports, several studies have shown paradigms leading to performance improvements prior to competition (i.e. taper; Aubry et al., 2014).

Despite the large amount of research related to training periodization and performance in team-sports (Gabbett and Domnrow, 2007; Gaudino et al., 2015; Manzi et al., 2010), limited data are available regarding planning of effective tapering strategies leading to performance enhancement prior to competition (Freitas et al., 2014; Nunes et al., 2014). In water-polo, the existing scientific literature is mainly related to heart rate measures obtained during training (Botonis et al., 2015; Lupo et al., 2014a) and validity of the heart rate as a means to estimate the internal training load (Lupo et al., 2014a). Given that players participate in an extensive year-round competitive period, careful monitoring of training is required for effective tapering when approaching the period of play-offs. However, there is limited valid information concerning planning of training the weeks before play-offs.

Monitoring the post-session rate of perceived exertion (session-RPE) has been provided as a valid method for internal training load (ITL) quantification and this has been effectively applied in water-polo (Lupo et al., 2014a) as well as in swimming (Barroso et al., 2014) and dry-land team-sports (Buchheit et al., 2013; Coutts and Reaburn, 2008; Moreira et al., 2015). Furthermore, monitoring training monotony and strain (Anderson et al., 2003) along with wellness (Saw et al., 2015) and performance, assures a more comprehensive view of each player's physical status. Despite this approach provides valuable information to the coach, it is not clear whether an imposed external load will be effectively reflected in the internal load perceived by players of teamsports such as water-polo, where the imposed internal load may vary significantly between players due to the diverse range of training activities commonly employed. In this case, revealing any dissociation between the external and internal load may protect players from inappropriate loading.

Whatever the case, the practical application of the external load manipulation and its influence on changes of the internal load and performance has never been previously examined.
Moreover, although the session-RPE method has often been criticized for weaknesses, its practical applicability and usefulness to measure the ITL overcomes them (Impellizzeri et al., 2004). As none of the methods used to quantify training loads can provide an accurate calculation of the ITL (all methods just estimate the training load), further research concerning this issue should be conducted in water-polo. The findings of the study would help coaches to design effective training plans aiming at maximizing water-polo performance. Therefore, the aim of the current study was to examine the effects of a planned short duration period including an overloading training phase (2 weeks) and a progressive training load reduction phase (tapering; 2 weeks) on the ITL, wellness variation and sport-specific swimming performance in high-level water-polo players. It was hypothesized that changes in the external load through daily training volume manipulation would be related to internal load changes and performance indices during a short period in highlevel water-polo players.

\section{Methods}

\section{Participants}

Eleven male outfield water-polo players with a minimum of $5.6 \pm 3.9$ years of playing experience in the top level Greek league, volunteered to participate in the study. Three of them did not reach the compliance rate of $80 \%$ due to illness or injury and were excluded from final data analysis. As a result, eight athletes (age: $25 \pm 7$ years; body height: $181 \pm 5 \mathrm{~cm}$; body mass: $84 \pm 7$ $\mathrm{kg}$ ) completed the study. Before commencing the study, the players participated in the regular season and finally were classified at the second position of the national league ranking. At the end of the in-season period, all players participated in seven training sessions per week covering an average weekly volume of $572 \pm 15 \mathrm{~min}$ (Table 1 ). However, during the pre-season period the same players participated in eight to ten training sessions per week approaching a volume of about $900 \mathrm{~min}$ ( $15 \mathrm{~h}$ per week). All participants provided a written informed consent form before the commencement of the study. The study was approved by the Faculty review board and conformed to the Declaration of Helsinki.

\section{Measures}

The ITL was measured using the session- 
RPE for all training sessions and matches. The session-RPE was derived by asking each player "How intense was your session/match?" according to the Borg's CR-10 scale, where $0=$ nothing at all and $10=$ very very hard (Foster et al., 2001), 30 min after each training session or match. Players were asked to ensure that their rating of perceived exertion (RPE) referred to the intensity of the whole session rather than the most recent exercise completed. A fifteen-day period was used for familiarization with the RPE scale before the commencement of the experimental data collection. The quantification of the ITL was calculated by multiplying training intensity (i.e. session-RPE) by the training session or match duration. Training intensity was divided into three zones according to the Borg CR-10 RPE scale (low, $\leq 4 \mathrm{AU}$; moderate, above 4 and below 7; and high $>7$ ) (Moreira et al., 2015).

The duration of training sessions included the entire session (from warm-up to cool down activities), whereas for matches, individual playing time was used including all stops (game stops, injury stops and time-outs). The individual ITL was computed on a daily basis and the average session-RPE of the week was calculated. The sum of all training sessions of the week was computed to obtain the weekly training load. Moreover, the monotony was calculated by dividing the mean individual internal training load by the standard deviation of the weekly internal training load and the physiological strain imposed on players was calculated by multiplying the monotony to the mean weekly load (Foster et al., 2001). A psychometric questionnaire (Hooper and Mackinnon, 1995) was used to assess general indicators of players' wellness. The questionnaire was comprised of five questions related to perceived fatigue, sleep quality, general muscle soreness, stress levels and mood with each question scored on a five-point scale (McLeanet al., 2010). The questionnaire was completed daily upon awakening and concerned the preceding daily training load. The overall wellness was then determined by summing the five scores.

Two days before the commencement of the intervention (baseline) as well as one day after the end of overloading and tapering phases, players' performance was evaluated through 400-m and 20mswimming performance tests. The above mentioned tests have been suggested as water- polo-specific performance indexes (Botonis et al., 2016; Ramos Velizet al., 2014) reflecting players' ability to maintain physical and technical performance within a match $(400 \mathrm{~m})$ and their anaerobic power and speed $(20 \mathrm{~m})$. Participants performed both tests in pairs to ensure a motivated effort with the race start in the water. Two of the investigators with more than 10 years of timekeeping experience in swimming events served as time keepers in all occasions (Eagle, Accusplit, California, USA).

\section{Procedures}

Towards the completion of the first phase of the championship (in-season period), a fourweek training mesocycle that preceded the start of play-offs was applied and divided into two distinct phases with different training content and loading: the first period (overloading phase; weeks 1 and 2) and the second period (tapering; weeks 3 and 4). This four-week training program was designed in cooperation with the head coach of the club in to maximize swimming performance of the waterpolo players and to help them reach competitive readiness. During weeks 3 and 4, the training load was intentionally and progressively decreased. This was achieved by a day to day manipulation of the external training volume and intensity as it is described in the following paragraph.

During the in-season period, the training program was designed and conducted by the head coach with no input from the researchers. The program habitually consisted of seven training sessions, each lasting up to $90 \mathrm{~min}$, including strength and conditioning sessions, as well as technical and tactical training. Regularly, one official match was played at the end of each week. Two weeks before thecompletion of the in-season period, an overload training program was imposed on the players. In particular, training frequency was increased to 9-11 sessions per week, each lasting from 60 to $90 \mathrm{~min}$. Compared to previous habitual training, the prescribed training volume in week 1 and 2 of overloading training was increased by $52.0 \pm 5.9$ and $36.0 \pm 1.7 \%$, respectively. Regarding intensity, $60 \%$ of all sessions were rated as moderate and $33 \%$ as of high intensity. Morning training sessions included dryland or in-water strength and conditioning sessions. Afternoon sessions included water-polo 
specific drills (technical and tactical training). The selected players also participated in one friendly match at the second week of investigation. One day-off was given both at week 1 and 2, respectively (Table 1 ).

The average training volume of weeks 3 and 4 (taper phase) was reduced by $25.8 \pm 2.6 \%$ compared to weeks 1 and 2 (overload phase). Strength and conditioning training was reduced and more training time was devoted to technical/tactical preparation as well as friendly matches. Accordingly, training intensity was increased with $36 \%$ of the sessions being rated as moderate and $57 \%$ as of high intensity. A two-day rest was given to the players at the fourth week of training (Table 1).

\section{Statistical Analysis}

Before using parametric statistical test procedures, the normality of the data was verified by the Shapiro-Wilk test. Analysis of variance for repeated measurements on dependent samples was employed to detect differences between training phases in exercise performance, ITL, overall wellness, monotony and strain. A Tukey post-hoc test was used for multiple comparisons. Standardized differences in means (effect sizes, $d$ ) were computed for pairwise comparisons. As a measure of effect size the Cohen's $d$ was calculated dividing the difference between sample means by the standard deviation of difference scores. The magnitude of each effect size was classified as trivial $(d<0.2)$, small $(d=0.2-0.6)$, moderate $(d=$ $0.6-1.2)$, large $(d=1.2-2.0)$, very large $(d=2.0-4.0)$, and extremely large $(d>4.0)$ (Hopkins, 2010). The correlation coefficient $(r)$ was used to test the associations between changes $(\Delta)$ in performance variables and the respective changes in the ITL, wellness, sleep quality, fatigue perception, muscle soreness, stress level and mood state across the training weeks. The results are presented as means \pm standard deviations (SD) and statistical significance was set at $p<0.05$.

\section{Results}

The weekly ITL, strain, monotony and wellness are presented in Table 2 and daily variation of the ITL and wellness is depicted in Figure 1. In weeks 3 and 4 , the ITL was reduced compared to week 1 by $19.0 \pm 3.8$ and $36.0 \pm 4.7 \%$, respectively $(p=0.00, d=24.01$ and $p=0.00, d=$
34.09 , respectively). In week 4 , the ITL was lower compared to all previous weeks (Table 1). Similarly, both physiological strain and monotony were greater in week 1 compared to all subsequent weeks ( $p=0.001$ and $p=0.001$, Table 1$)$ and no differences were observed between weeks 2,3 and 4 ( $p>0.05$, Table 2).

Furthermore, wellness scores were increased as training phases progressed $(p<0.001$, Table 2) being higher in the tapering than overloading phase $(p=0.001$, Table 2). Perceived wellness was alike between week 1 and week $2(p$ $=0.38, d=0.49)$ and also similar between week 2 and week $3(p=0.23, d=0.94)$. Additionally, players reported greater wellness scores throughout week 4 compared to weeks 1 and 2 of the overloading phase $(p=0.001, d=1.46$ and $p=0.001, d=2.28$, respectively), but similar to those displayed in week $3(p=0.23$, Table 2$)$.

Players' swim performance time is depicted in Figure 2. No differences were found between the mean 400-m and 20-m swim times when the baseline values and those from the end of the overloading training period were compared $(p$ $=0.19, d=0.55$ and $p=0.89, d=0.22$, respectively). On the other hand, 400-m swim performance was improved by $0.8 \pm 0.6$ and $1.3 \pm 0.8 \%$ at the end of week 4 compared to baseline ( $p=0.03, d=1.34)$ and week $2(p=0.00, d=1.68)$. Likewise, $20-\mathrm{m}$ swimming performance improved by $2.1 \pm 2.2$ and $2.5 \pm 2.8 \%$, at the end of week 4 compared to baseline ( $p=0.05, d=0.95)$ and week $2(p=0.02, d=$ 0.89).

Correlation coefficients between ITL changes (\%) and the respective changes in performance indices and wellness scores across the four-week training period are depicted in Table 3. A high correlation was observed between the percentage change $(\Delta \%)$ in the ITL between weeks 4 and $1(\Delta \%$ $4-1)$ and performance change in the 20-m swim sprint in the same period $(\mathrm{r}=0.88, p=0.00)$. The respective $400-\mathrm{m}$ time change was not related to $\Delta \%$ 4-1 $(\mathrm{r}=0.65, p=0.09)$. Throughout training, the daily ITL was moderately correlated with the wellness score reported the following morning $(\mathrm{r}=$ $-0.45, p=0.00$ ). 

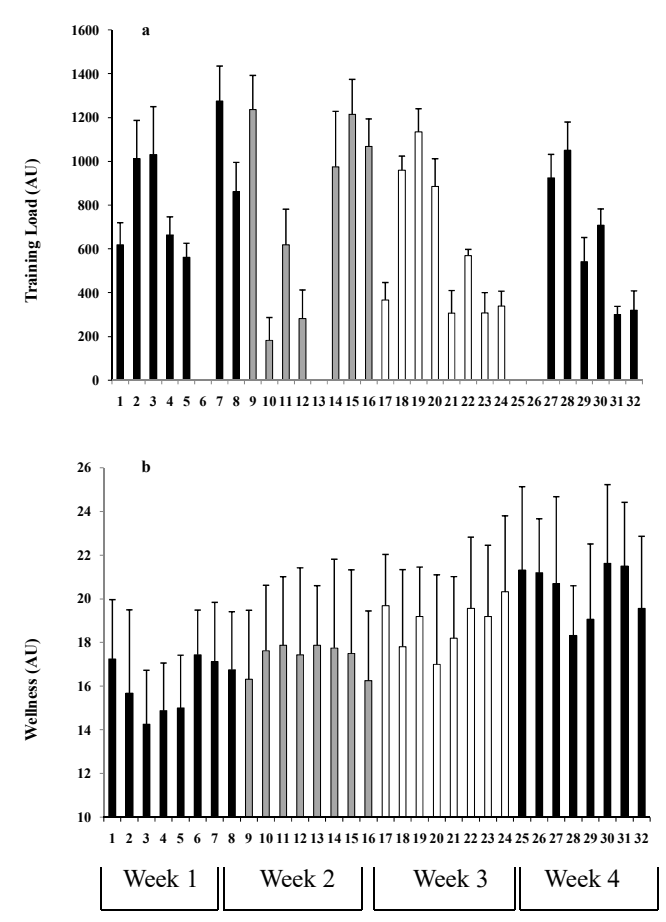

Figure 1

Daily internal training load (upper panel a) and wellness scores (lower panel b) throughout overloading (weeks 1 and 2) and tapering training (weeks 3 and 4$)(n=8$, mean $\pm S D)$.

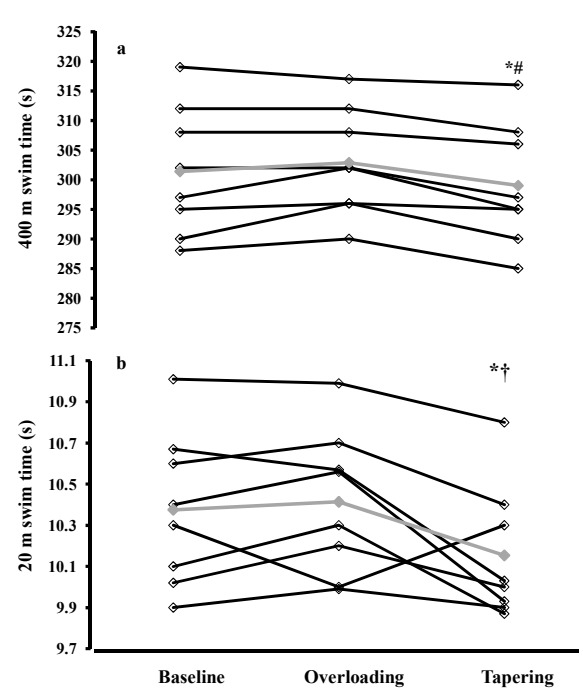

Figure 2

Individual performance time for (a) $400 \mathrm{~m}$ swim and (b) $20 \mathrm{~m}$ swim at baseline and at the end of overloading and tapering training phases. The grey line represents mean values for each testing period $(n=8)$. *: $p \leq 0.05$ between tapering and baseline, $\#: p \leq 0.01$ between tapering and overloading, $t: p \leq 0.05$ between tapering and overloading. 
Table 1

Training characteristics and the mean session rating of perceived exertion (RPE) during two weeks of normal in-season training as well as in overloading (weeks 1 and 2) and tapering (weeks 3 and 4 ) training phases $(n=8$, mean $\pm S D$ ).

\begin{tabular}{|c|c|c|c|c|c|}
\hline & \multirow{2}{*}{$\begin{array}{c}\text { Normal in-season } \\
\text { training }\end{array}$} & \multicolumn{2}{|c|}{ Overloading training } & \multicolumn{2}{|c|}{ Tapering training } \\
\hline & & Week 1 & Week 2 & Week 3 & Week 4 \\
\hline $\begin{array}{l}\text { Weekly volume } \\
(\mathrm{min})\end{array}$ & $572 \pm 15$ & $870 \pm 0$ & $778 \pm 27$ & $654 \pm 21$ & $569 \pm 11$ \\
\hline $\begin{array}{l}\text { Weekly Strength and } \\
\text { Conditioning training time } \\
(\mathrm{min})\end{array}$ & $210 \pm 11$ & $475 \pm 23$ & $435 \pm 30$ & $165 \pm 33$ & $165 \pm 29$ \\
\hline $\begin{array}{l}\text { Weekly Technical and } \\
\text { Tactical training time } \\
\text { (min) }\end{array}$ & $300 \pm 10$ & $395 \pm 28$ & $265 \pm 33$ & $365 \pm 29$ & $365 \pm 17$ \\
\hline Matches (number) & 2 & - & 2 & 3 & 1 \\
\hline $\begin{array}{l}\text { Individual mean match } \\
\text { time (min/week) }\end{array}$ & $31 \pm 11$ & - & $39 \pm 13$ & $41 \pm 9$ & $39 \pm 11$ \\
\hline $\begin{array}{l}\text { Day-off } \\
\text { (number/week) }\end{array}$ & 1 & 1 & 1 & - & 2 \\
\hline Mean RPE & & $6.91 \pm 0.51$ & $6.69 \pm 0.96$ & $6.97 \pm 0.40$ & $6.85 \pm 0.41$ \\
\hline
\end{tabular}

\section{Table 2}

Internal training load, strain, monotony and overall wellness during overloading (weeks 1 and 2 ) and tapering (weeks 3 and 4 ) training phases ( $n=8$, mean $\pm S D)$.

\begin{tabular}{|c|c|c|c|c|c|c|c|c|c|c|}
\hline \multirow[b]{2}{*}{ Variable } & \multirow[b]{2}{*}{ Week 1} & \multirow[b]{2}{*}{$\begin{array}{c}\text { Week } \\
2\end{array}$} & \multirow[b]{2}{*}{$\begin{array}{c}\text { Week } \\
3\end{array}$} & \multirow[b]{2}{*}{$\begin{array}{c}\text { Week } \\
4\end{array}$} & \multicolumn{6}{|c|}{$d$ and $p$ (within brackets) values of each comparison } \\
\hline & & & & & $\begin{array}{c}\text { week } \\
1-2\end{array}$ & $\begin{array}{c}\text { week } \\
1-3\end{array}$ & $\begin{array}{c}\text { week } \\
1-4\end{array}$ & $\begin{array}{c}\text { week 2- } \\
3\end{array}$ & $\begin{array}{c}\text { week 2- } \\
4\end{array}$ & $\begin{array}{c}\text { week 3- } \\
4\end{array}$ \\
\hline $\begin{array}{c}\text { Internal } \\
\text { training } \\
\text { load } \\
(\mathrm{AU})\end{array}$ & $\begin{array}{r}6026 \\
\pm 501\end{array}$ & $\begin{array}{r}5580 \\
\pm 806\end{array}$ & $\begin{array}{l}5519 \\
\pm 366\end{array}$ & $\begin{array}{r}3550 \\
\pm 325\end{array}$ & $\begin{array}{c}0.5 \\
(1.0)\end{array}$ & $\begin{array}{c}3.2 \\
(0.00)\end{array}$ & $\begin{array}{c}5.9 \\
(0.00)\end{array}$ & $\begin{array}{c}0.8 \\
(0.36)\end{array}$ & $\begin{array}{c}3.3 \\
(0.00)\end{array}$ & $\begin{array}{r}6.2 \\
(0.00)\end{array}$ \\
\hline $\begin{array}{c}\text { Strain } \\
(\mathrm{AU})\end{array}$ & $\begin{array}{l}2627 \\
\pm 172\end{array}$ & $\begin{array}{l}1472 \\
\pm 455\end{array}$ & $\begin{array}{l}1088 \\
\pm 155\end{array}$ & $\begin{array}{l}1316 \\
\pm 227\end{array}$ & $\begin{array}{r}2.0 \\
(0.00)\end{array}$ & $\begin{array}{c}5.5 \\
(0.00)\end{array}$ & $\begin{array}{r}4.2 \\
(0.00)\end{array}$ & $\begin{array}{c}1.1 \\
(0.18)\end{array}$ & $\begin{array}{c}0.4 \\
(0.78)\end{array}$ & $\begin{array}{c}1.2 \\
(0.55)\end{array}$ \\
\hline $\begin{array}{l}\text { Monotony } \\
\text { (AU) }\end{array}$ & $\begin{array}{c}3.1 \\
\pm 0.3\end{array}$ & $\begin{array}{c}1.8 \\
\pm 0.4\end{array}$ & $\begin{array}{c}1.8 \\
\pm 0.2\end{array}$ & $\begin{array}{c}2.1 \\
\pm 0.3\end{array}$ & $\begin{array}{c}2.3 \\
(0.00)\end{array}$ & $\begin{array}{c}3.1 \\
(0.00)\end{array}$ & $\begin{array}{c}2.6 \\
(0.00)\end{array}$ & $\begin{array}{c}0.1 \\
(1.0)\end{array}$ & $\begin{array}{c}0.6 \\
(0.60)\end{array}$ & $\begin{array}{c}0.9 \\
(0.51)\end{array}$ \\
\hline $\begin{array}{l}\text { Wellness } \\
(\mathrm{AU})\end{array}$ & $\begin{array}{r}16.0 \\
\pm 2.2\end{array}$ & $\begin{array}{r}17.3 \\
\pm 2.9\end{array}$ & $\begin{array}{r}18.9 \\
\pm 2.9\end{array}$ & $\begin{array}{r}20.4 \\
\pm 2.8\end{array}$ & $\begin{array}{c}0.5 \\
(0.39)\end{array}$ & $\begin{array}{c}0.6 \\
(0.00)\end{array}$ & $\begin{array}{c}1.5 \\
(0.00)\end{array}$ & $\begin{array}{c}0.9 \\
(0.23)\end{array}$ & $\begin{array}{c}2.3 \\
(0.00)\end{array}$ & $\begin{array}{c}1.2 \\
(0.23)\end{array}$ \\
\hline
\end{tabular}


Table 3

Correlation coefficients between percentage changes in the internal training load (ITL) and the respective changes in performance indices and wellness scores during four weeks of training in eight national-level water-polo players. $\Delta$ ITL 2-1: percentage change in the mean ITL between week 2 and week 1, IITL 3-1: percentage change in the mean ITL between week 3 and week 1,

$\Delta$ ITL 4-2: percentage change in the mean training load between week 4 and week 2,

$\Delta$ ITL 4-1: percentage change in the mean training load between week 4 and week $1,{ }^{*} p<0.05,{ }^{* *} p<0.01$.

\begin{tabular}{ccccc}
\hline Percentage changes $(\%)$ & $\Delta$ ITL 2-1 & $\Delta$ ITL 3-1 & $\Delta$ ITL 4-2 & $\Delta$ ITL 4-1 \\
\hline$\Delta 20 \mathrm{~m} \%$ & 0.31 & - & -0.21 & $0.88^{* *}$ \\
$\Delta 400 \mathrm{~m} \%$ & 0.32 & - & 0.11 & 0.65 \\
$\Delta$ Wellness \% & 0.42 & 0.52 & 0.28 & $0.75^{*}$ \\
$\Delta$ Sleep \% & -0.13 & -0.54 & 0.54 & -0.65 \\
$\Delta$ Fatigue \% & -0.51 & -0.41 & 0.27 & $-0.79^{*}$ \\
$\Delta$ Soreness \% & -0.68 & -0.39 & 0.41 & $-0.78^{*}$ \\
$\Delta$ Mood \% & -0.08 & -0.37 & -0.64 & -0.51 \\
$\Delta$ Stress \% & -0.23 & -0.32 & -0.23 & $-0.70^{*}$ \\
\hline
\end{tabular}

High correlations were also observed between the percentage reduction of the ITL (week 4-1) and the respective changes in fatigue perception, muscle soreness, stress levels and the overall wellness scores $(r=0.74-0.79, p<0.05)$, while there was a tendency for significance with the percentage changes in sleep quality $(\mathrm{r}=-0.65, p=$ 0.08 ). Moreover, performance changes (week 4-1) in the $20 \mathrm{~m}$ and $400 \mathrm{~m}$ swims were highly correlated $(r=0.85, p=0.001)$.

\section{Discussion}

The current study examined, in a realtraining setting, changes of the ITL, swimming performance and wellness within a short period leading to the national play-offs in one of the most competitive national water-polo championships worldwide. The main findings are that: a) a training load increase in the overloading phase deteriorated wellness scores, but had no significant detrimental effect on sport-specific performance indices of the players compared to baseline; $b$ ) the progressive, exponential reduction in training volume and frequency induced a meaningful decline in the ITL and subsequently improved wellness scores and sport-specific performance measures of the players at the end of the intervention compared to baseline and the end of overloading training; c) the change in 20-m sprint swim time (week 4 vs. week 1 ) was correlated with the respective change in the ITL.

In accordance with our initial hypothesis, the ITL variation was aligned with the preprogrammed training phases of overloading and reduced training volume. This coincides with previous suggestions that session-RPE monitoring is a valid method for quantifying training loads in water-polo (Lupo et al., 2014a). Moreover, we showed that daily monitoring of players' RPE along with recording specific training characteristics and subsequent wellness responses of the players might be useful and practical tools 
for practitioners aiming at teams' competitive readiness before the commencement of critical matches. This is new and practically useful information. The present findings suggest that an appropriate manipulation of water-polo teamtraining content the weeks prior to major competition may have positive effects on players' sport-specific performance and recovery status.

In the current study, two weeks of postseason intensified training were characterized by increased physiological strain and monotony, moderate to severe fatigue perception, increased muscle soreness as well as disrupted sleep quality. Despite that, overloading training resulted in a moderate descent of swimming performance in both the $400-\mathrm{m}$ and $20-\mathrm{m}$ swim times, suggesting that players responded adequately to the imposed training loads in the first two weeks of this short training cycle. Similar observations have also been reported in elite female swimmers (Raglin et al., 1996). In contrast, Coutts and Reaburn (2008) observed that the increments of the ITL during a six-week overloading period were accompanied by important decrements in exercise performance of the participants. It seems that the two-week period was sufficient to maintain performance without causing any detrimental effects. On the other hand, this manipulation was proven effective for performance enhancement after an appropriate training load reduction during subsequent weeks 3 and 4 .

Noteworthy, the taper period (weeks 3 and 4) induced meaningful gains both in the 400-m and 20-m swimming speed. The improvement in 400-m swimming mirrors an enhanced conditioning level and most importantly indicates an improved players' potential to maintain performance throughout the match (Botonis et al., 2016). This gain $(0.8-1.3 \%)$, however, is in the lower range of taper-induced performance gains reported in the literature (i.e. 0.5 - 6\%) (Mujika et al., 2004). The amplitude of performance gains is inversely related to the participants' caliber (Mujika et al., 2004) as well as to the amplitude of training volume reduction (Mujika et al., 1995). In fact, lower-level swimmers have been shown to achieve greater performance improvements (4.9 - 15.6\%) after a two-week tapering period (Johns et al., 1992). In this line, although the reduction of training volume in the fourth week corresponded to $50 \%$ of the first week of training, the respective reduction in the internal training load corresponded to $36 \%$. This might be attributed to the observed differences between players in real playing time during preparation matches indicating that the training load was not equally distributed among them.

Additionally, the considerable improvements $(2.0-2.5 \%)$ for the $20-\mathrm{m}$ swim time most possibly are due to taper-induced neuromuscular adaptations (Papoti et al., 2007). The very large correlation observed between percentage changes in training loads (week 4-1) and the respective change in the $20-\mathrm{m}$ swim performance suggests that swimming sprint gains can be explained by ITL reduction and that planning tapering in water-polo should be based on training load quantification. Besides, the large effect size found for both 400-m and 20-m swim tests indicates that the application of such a training paradigm in a real training setting may result in important benefits in endurance and sprint performance of well-trained water-polo players.

Interestingly, the day to day measures of the ITL were correlated with the subjective measures of wellness. This coincides with findings of Buchheit et al. (2013) supporting the sensitivity of wellness measures to the ITL and offers important information regarding the acute training response and recovery the following day. In accordance to this, previous studies in swimming have also shown positive alterations after tapering in psychological measures such as a mood state and quality of sleep (Hooper et al., 1998; Raglin et al., 1996). Moreover, the observed large correlations between the percentage reduction of the ITL (week 4-1) with the respective changes in the overall wellness scores and performance indices show that performance peaks during the taper period through fatigue dissipation (Mujika, 2009) and wellness improvement.

We should also consider that the average training volume of our high-level water-polo players, participating in one of the most competitive national water-polo championships worldwide, was lower than that previously observed. Canossa et al. (2014) reported that highlevel Spanish players participated in training sessions lasting on the average $23 \mathrm{~h}$ per week. The subjects of the current study completed about $10 \mathrm{~h}$ of training per week during the study period, 
however, they had completed similar to high-level Spanish players training volume during the preseason training period (i.e. $15 \mathrm{~h}$ per week). Furthermore, except for the training volume, other training characteristics such as exercise intensity and the players' rate of perceived exertion were not provided in the study of Canossa et al. (2014) and thus, direct comparisons between players competing in Greek and Spanish water-polo championships are not recommended. Whatever the case, the training background of players is a critical factor affecting the mode of training volume and load decrement during the taper period.

We acknowledge several limitations associated with our study, which include the lack of a control group, the absence of physiological/objective measures and the time recording of the 20-m test by timekeepers. However, employing a control group in real training conditions is almost impossible due to pragmatic constraints, thus making the recruitment of similar level players as a control group difficult. Moreover, although the employment of physiological measurements would have strengthened our conclusions, it appears that subjective measures are equally important as they have been shown to be advantageous in some cases over objective measures, reflecting acute and chronic training loads with superior sensitivity and consistency compared to objective measures (Saw et al., 2015). It should be stated, however, that although the RPE reflects an integration of afferent neural signals from various physiological systems to the brain (Abbiss et al., 2015), the existing literature has shown large variations between the RPE method and heart rate measures (Impellizerri et al., 2004; Lupo et al., 2014) and as such more research is required to clarify its validity as a measure of the ITL. Along this line, it would also be useful to measure technical and/or tactical indices of players. However, this was impossible due to the time constraints imposed by the real competitive demands of the championship. The current results are unique in that high-level water-polo players were monitored for the first time, providing clear evidence for appropriate training and recovery before a major post-season play-off competition at the national level.

To summarize, the current data suggest that an appropriate post-season manipulation of the external training load is effectively reflected by internal training load changes inducing important improvements in general well-being and considerable gains in sport-specific performance measures. The progressive exponential reduction of training loads up to $\sim 36 \%$ in the last week of training is an effective tapering strategy in the leadup to play-offs tournament.

\section{Acknowledgements}

We would like to thank the players for the participation in this study and the coach: TheofanisKountoudios for his cooperation.

\section{References}

Abbiss CR, Peiffer JJ, Meeusen R, Skorski S. Role of ratings of perceived exertion during self-paced exercise: what are we actually measuring? Sports Med, 2015; 45: 1235-1243

Andersson L, Triplett-McBride T, Foster C, Doberstein S, Brice C. Impact of training patterns on incidence of illness and injury during a women's collegiate basketball season.J Strength Cond Res, 2003; 17: 734-738

Aubry A, Hausswirh C, Louis J, Coutts AJ, LE Meur Y. Functional overreaching: the key to peak performance during the taper? Med Sci Sports Exerc, 2014; 46: 1769-1777

Barroso R, Cardoso RK, do Carmo EC, Tricoli V. Perceived exertion in coaches and young swimmers with different training experience.Int J Sports Physiol Perform, 2014; 9: 212-216

BosquetL, Montpetit J, Arvisais D, Mujika I. Effects of tapering on performance: a meta-analysis.Med Sci Sports Exerc, 2007; 39: 1358-1365 
Botonis PG, Toubekis AG, Platanou TI. Physiological responses of water-polo players under different tactical strategies. J Sports Sci Med, 2015; 14: 84-90

Botonis PG, Toubekis AG, Terzis GD, Geladas ND, Platanou TI. Performance decrement and skill deterioration during a water polo game are linked with the conditioning level of the athletes. J Strength Cond Res, 2016; 30, 1033-1041

Buchheit M, Racinais JC, Bilborough JC, Burdon PC, Voss SC, Hocking J, Cordy J, Mendez-Villanueva A, Coutts AJ. Monitoring fitness, fatigue and running performance during a pre-season training camp in elite football players. J Sci Med Sport, 2013; 16: 550-555

Canossa S, Abraides JA, Soares S, Vila MH, Rodriguez N, Argudo FM, Fernandes RJ, Garganta JM. Contrasting morphology and training background in waterpolo teams of different competitive levels. Motritz, Rio Claro, 2014; 20: 272-279

Coutts AJ, Reaburn P. Monitoring changes in rugby league players' perceived stress and recovery during intensified training. Percept Motor Skills, 2008; 106: 904-916

Foster C, Florhaug JA, Franklin J, Gottschall L, Hrovatin LA, Parker S, Eads M, Dodge C. A new approach to monitoring exercise training. J Strength Cond Res, 2001; 15: 109-115

FreitasCG,Aoki MS,Franciscon CA,Arruda AF,Carling C, Moreira A. Psychophysiological responses tooverloadingand tapering phases in elite youngsoccerplayers.PediatrExercSci, 2014;26: 195-202

Gabbett TJ, Domrow N. Relationships between training load, injury, and fitness in sub-elite collision sport athletes. J Sports Sci, 2007; 25: 1507-1519

Gaudino P, Iaia FM, Strudwick AJ, Hawkins RD, Alberti G, Atkinson G, Gregson W. Factors influencing perception of effort (session rating of perceived exertion) during elite soccer training. Int J Sports Physiol Perform, 2015; 10: 860-864

HooperSL,MackinnonLT. Monitoring overtraining in athletes. Recommendations.Sports Med, 1995; 20: 321-327

HooperSL,Mackinnon LT,Howard A. Physiological and psychometric variables for monitoring recovery during tapering for major competition. Med Sci Sports Exerc,1998; 31: 1205-1210

Hopkins WG. Linear models and effect magnitudes for research, clinical and practical applications. Sportscience, 2010; 14: 49-57

Impellizzeri FM, Rampinini E, Coutts AJ, Sassi A, Marcora SM. Use of RPE-based training load in soccer. Med Sci Sports Exerc, 2004; 36: 1042-1047

Johns RA, Houmard JA, Kobe RW, Hortobágyi T,Bruno NJ,Wells JM,Shinebarger MH. Effects of taper on swim power, stroke distance and performance. Med Sci Sports Exerc, 1992;24: 1141-1146

Lupo C, Capranica L, Tessitore A. The validity of session-RPE method for quantifying training load in water polo. Int J Sports Physiol Perform, 2014a; 9: 656-660

Lupo C, Condello G, Capranica A. Women's water polo world championships: technical and tactical aspects of winning and losing teams in close and unbalanced games. J Strength Cond Res, 2014b; 28: 210-222

Manzi V, D'Ottavio S, Impellizzeri FM, Chaouachi A, Chamari K, Castagna C. Profile of weekly training load in elite male professional basketball players. J Strength Cond Res, 2010; 24: 1399-1406

McLeanBD, Coutts AJ,Kelly V,McGuigan MR,Cormack SJ. Neuromuscular, endocrine, and perceptual fatigue responses during different length between-match microcycles in professional rugby league players.Int J Sports Physiol Perform, 2010;5: 367-383

Moreira A, Bilsborough JC, Sullivan CJ, Ciancosi M, Aoki MS, Coutts AJ. Training periodization of professional Australian football players during an entire Australian Football League season. Int J Sports Physiol Perform, 2015; 10: 566-571

Mujika I. Tapering and peaking for optimal performance.Champain, IL: Human kinetics; 2009

Mujika I, Chatard JC,BussoT,Geyssant A,Barale F,Lacoste L. Effects of training on performance in competitive 
swimming. Can J ApplPhysiol, 1995; 20: 395-406

Mujika I, Padilla S, Pyne D, Busso T. Physiological changes associated with the pre-event taper in athletes. Sports Med, 2004; 34: 891-927

NunesJA, Moreira A, Crewther BT, Nosaka K, Viveiros L, Aoki MS. Monitoring training load, recovery-stress state, immune-endocrine responses, and physical performance in elite female basketball players during a periodized training program.J Strength Cond Res, 2014;28: 2973-2980

Papoti M, Martins LE, Cunha SA, Zagatto AM, Gobatto CA.Effects of taper on swimming force and swimmer performance after an experimental ten-week training program. J Strength Cond Res, 2007;21: 538-542

Raglin JS, Koceja DM, Stager JM, Harms CA. Mood, neuromuscular function, and performance during training in female swimmers.Med Sci Sports Exerc, 1996; 28: 372-377

Ramos Veliz R,Requena B,Suarez-Arrones L,Newton RU,Sáez de Villarreal E. Effects of 18-week in-season heavy-resistanceand powertrainingon throwing velocity,strength, jumping, and maximal sprint swim performance of elite malewaterpoloplayers. J Strength Cond Res, 2014;28: 1007-1014

Saw AE, Main LC, Gastin PB. Monitoring the athlete training response: subjective self-reported measures trump commonly used objective measures: a systematic review. Br J Sports Med, 2015; 0: 1-13

\section{Corresponding author:}

\section{Petros G. Botonis}

Department of Aquatic Sports, School of Physical Education and Sports Science,

University of Athens, Athens, Greece.

-41, Ethnikis Antistasis Ave, 17237, Dafni, Greece.

Phone: +302107276065; +306974709907,

E-mail: pboton@phed.uoa.gr 